\title{
METHODOLOGICAL CHALLENGES IN THE STUDY OF TECHNOLOGY USE AT HOME
}

\author{
Arne Kjaer ${ }^{1}, K_{\text {Kim Halskov Madsen }}^{1}$ and Marianne Graves Petersen ${ }^{2}$ \\ ${ }^{1}$ Information and Media Science, Aarhus University, Aarhus, Denmark. \\ ${ }^{2}$ Dept. of Computer Science, Aarhus University, Denmark
}

Key words: Home-IT, television set, field study, qualitative methods, evolution in use.

\begin{abstract}
Based on the planning and conduction of a longitudinal field study of the use of television sets in the homes of two families, we discuss how approaches like field studies which are otherwise well established when designing for work practices, becomes questionable when transferred to a home setting where the issue of privacy is prevalent. The fairly sporadic operation of a TV set poses additional methodological challenges. Furthermore, we point out how our general concern of designing for development in use becomes even more relevant with the introduction of interactive technology in the home sphere. Key elements of the approach applied include: hands-on in context, incident diaries, scenarios, iterative and explorative investigation, and role playing.
\end{abstract}

\section{NEW CHALLENGES}

There is a growing concern within the area of $\mathrm{HCI}$ that the spreading of interactive technology into all aspects of everyday life, including private homes, offers new challenges for the design of home IT $[15,19]$. When designing interactive technology for workplaces, field studies are among the prevailing approaches for establishing an understanding of the practice and context in which the future design will exist, and in turn for identifying requirements for the technology being developed [2, 9]. However, when conducting field studies of the use of information technology in a private home setting, issues such as privacy and sporadic use calls for a revision of the way of entering the field. In this article we address some of the corrected. The Erratum to this chapter is available at DOI: 10.1007/978-0-387-35511-5_17 
methodological challenges of conducting field work and studying evolution in use in a home setting. We have a particular concern for evolution in use, an issue which is fairly ignored within the area of $\mathrm{HCI}$ [6]. This issue becomes even more important when designing home IT since, unlike the workplace, there is most often no formal training involved in getting to know the technology at home. This means the user relies even more on the design itself to get started to use the product as well as take advantage of more advanced features over time. Moreover, the sporadic use of technology depending not only on the situation of the family, but also the season and the weather - and the particular kind of social situation in which the technology is used, offers additional methodological challenges.

Our discussion of the methodological challenges in the domain of home IT concerns a longitudinal study of two families' use of a new television set. The product we have studied is an integrated television and video recorder from Bang \& Olufsen, which can be seen as representing the trend of increasing integration between different products. The two families each consist of four members, husband, wife and two children. One family is middle aged with two grown up children, the other is a family of younger parents with two small children. While one of the families has previously owned Bang \& Olufsen products and as such is familiar with the companyline, the other family is a new customer in the Bang \& Olufsen boutique. We first visited the families in their homes by the time their new televisions were delivered. Subsequently, we have visited them three times, with approximately one month in between. At each visit we interviewed the family members, and provided scenarios, [7], to frame some hands on use sessions with the television. We will describe the methods used and the rationale behind our choice in more depth in the main body of the article. We discuss some general challenges when conducting field studies at home with a particular focus on sporadic use and with an interest in understanding the nature of use as it evolves over time.

While others have studied technology in homes, they have most often been driven by different motives than that of designing some specific new technology. For instance at the early home IT conference, concerning home telematics [21], most of the papers deal with the social implications of the introduction of various technology in the household. Although social implications form part of the considerations in designing new technology, we agree with O'Brien et al [19] that what we need when designing new technology is more detailed insight than what one gets from surveys. In order to form a platform for design improvements we need to understand the motives behind the specific instances of use of technology and we need to gain insight at the level of the actual interaction with the technology. Moreover, it is generally acknowledged from the use of technology at 
workplaces that there may be great difference in how people talk about their use of technology and how they actually use the technology. Therefore, rather than using a quantitative approach involving a large number of users and using for instance a questionnaire, we argue for the need of a detailed qualitative study.

Our research interest in the end is the design of the technology and how this design may support the user in evolving his or her use. But before getting their, we must strive for a detailed understanding of use of technology at the expense of a general and context independent knowledge about use of technology. Since we want to investigate development in use as it happens in a real life context we need to extend the study over a longer period of time.

\section{METHODOLOGICAL CHALLENGES IN THE HOME}

Studying technology use in the home poses some challenges as compared to our well established practice doing this at the workplace. In the following, we discuss in particular how our relationships with users changes once we enter in their homes and how we need to revise parts of our methods. Secondly, we address the challenge of capturing sporadic use which is prevalent in the case of users watching television.

\subsection{The relationships with users in their homes}

When studying the use of home-IT, establishing contact with the users is more difficult or at least different from other users of IT. In establishing the initial contact with users, we have normally set this kind of arrangement with management. However, in this situation, no manager is in charge of the users. Secondly constructing as well as capturing collaborative sessions with the users in context is different in homes as opposed to the workplace.

In our study we established the first contact with our families through the boutique in which the users bought their television sets. We did consider lending out television sets to some friends and to study their use of the television. In the project we are collaborating with Bang \& Olufsen, who produces the equipment and who have lent us the products which we studied. Thus it would have been an easy option to lend out these televisions. We gave up this idea, however, because our acquaintances would know too much about the idea of the investigation and we could imagine how they would go for investigating the different functionalities. Besides, we wanted 
to study development in use and for this purpose, the motivation behind buying the product influences how people get started with using the product and since we wanted to study this process we were careful not to set up artificial situations in this respect. In the project we got in contact with the customers after they had decided to buy their new TV-set but before it got delivered.

Choosing to visit users which from the start had no interest nor any direct incentive in participating in our study and visiting them in their precious spare time in their private homes put limitations on how much of their time we could take up. We restricted our study to four visits, each of a duration of one and a half hours in the evening, because they were busy at work during the day. This is in line with others, e.g. O'brien et al. [19] who conducted three evening visits in families' homes "adopting a pragmatic as opposed to ethnomethodologically purist stance". This is in contrast to what we have done in workplace situations where workshops with users have often taken up a full working day sometimes even more.

Furthermore, at work it is the manager who in the end decides, what technology you may use, and whether you should participate in a research project. Our families have had the possibility not to participate - when first asked, but also after each visit, we offered them the option of interrupting their participation. We found that the limited number of visits as well as the fact that the users volunteered their time in this case resulted in careful participation by the users throughout the course of the study.

Once the initial contact with the users was established the study could start. In terms of recording these activities we find that extra caution must be taken in the home as compared to the workplace. An example is the recording of video in private homes. Videotaping people is generally considered to be a very productive way of acquiring knowledge about work practice and use of technology [23], but it is also a rather sensitive issue. Mackay [18] has explained about some of the general precautions that need to be taken when recording and subsequently using video for analysing users' interaction with technology such that misuse of the video material is avoided. The use of a camera is intrusive in the workplace but even more in peoples private home. Thus when entering in the home we must carefully consider to what extend we can use video taping. Moreover, there are practical and aesthetic problems with situating a camera in homes. Whereas video recording equipment often would be an acceptable add on to a workplace, such technology could certainly ruin the interior of a living room. Due to considerations on respecting the private sphere we are entering into, we ended up using videotaping only for the hands-on situations of the users. The interviews were not videotaped. Beforehand we told the users how we would use the tapes and we got their acceptance. 
Afterwards, when analyzing the development in use, the video tapes have been of great support in giving us the possibility to look over what actually happened in a specific situation. On the other hand, our experience was that even our own presence in the homes was from the outset an awkward situation which required a great deal of caution from our side on how to behave. This situation was different from similar situations at workplaces which after all are much more public spaces than what we meet in homes. Recording with the camera in the homes only made this situation come to a head. Thus in the homes we face the trade-off between obtaining a comprehensive record and respecting the privacy of the home setting. In the homes we need to be even more careful with recording video. Mackay's [18] precautions are therefore extremely relevant also in the home setting.

\section{$2.2 \quad$ Capturing sporadic use}

The use of television is sporadic on several levels. First, the amount of use depends largely on the time of the year, and even on the weather. Though it sounds banal, this has implications for planning a field study. For instance one of the families had their television installed in the middle of their summer holiday, and since it turned out that the weather was really nice during that period of time, they had not used the television very much, when we returned to them one month later. Secondly, watching television is a task which most of the time involves a limited amount of interaction. In our families, the daily use of television only covers limited interaction and it is not predictable when they try out new functionalities. The television is often turned on just after dinner and left on for the rest of the evening, with the parents of the family sometimes falling asleep in front of the television and waking up in the middle of the night, turning the TV off and wandering to bed. As can be seen, studying the interaction taking place in a natural situation involves staying with a family in very private situations over long periods of time, which is problematic for ethical as well as practical reasons. The challenge of our study is thus to find means to mirror and condense the families' focuses and interactions with the product in the limited amount of time we had available during our visits in their homes. The means should somehow bridge the gap between the time of use and the point in time we met the families. In designing our approach we have considered how others have approached related challenges.

Diaries have been used for different purposes and in different forms to construct a record of peoples activities in the absence of a designer or an evaluator. Baxter [1] has used diaries to capture events of learning in a laboratory test of the learnability of spreadsheets and Rieman [20] has constructed a diary form to capture learning in the use of technology in 
general at a workplace. Further, the area of remote usability testing offers some suggestions in this situation. Critical incident reports [8], combined automated logging and critical incident reports [12], are examples of this. In these examples, only Rieman [20] has studied the naturally occurring use of technology. In the rest of the examples, constructed tasks were provided for the users to perform while filling in the diary.

Inspired by Baxter's notion of an incident diary [1] we constructed our own incident diary to focus on learning incidents and interesting events. We expected that the selection of particularly interesting incidents would minimise the users' effort, because we would not disturb them too much in their private, relaxed situations at home. Secondly we were interested in studying the naturally occurring events in the houses since we had a focus on studying development in use and thus were cautious not to form the users' expectations nor to guide them in certain directions.

We considered asking the users to construct a video diary inspired by Blomberg et al [3] who have used video to document the work practice at a law office revolving around the use of documents in a file cabinet. Since the file cabinet was only used infrequently and for short periods at a time, they made the arrangement with the lawyer, that when ever he used file cabinet he turned on a video camera placed in his office. A similar idea could be introduced to users in homes: Mounting a camera in their living room for say 14 days or 1 month and whenever they use the remote control for things other than turning the television on and off or shifting between channels, they could turn the camera on. Whether users in homes will participate in such an experiment, time will show. We decided not to set up this kind of study due to our scepticism concerning the intimacy of the situations potentially being recorded in the home setting as well as for the practical arrangements

We also considered using automatic logging of the users' interaction with the television. Rosson [22] and Kay \& Thomas [13] have used this approach in the case of users' learning to use a word processor and Kaasgard [12] has applied this technique for evaluating web-pages of which the users are physically widely distributed, potentially situated in their homes. Obviously, this technique would be applicable and not very intrusive in the home setting. In the end we abandoned it partly due to technical obstacles. It is an approach we would consider to use in the future, however, we find in line with others [12] that this approach cannot stand on its own since it does not reveal the motivation and rationale behind the larger activities of the users nor the context in which the logged key-strokes takes place. Quantitative accounts of number of incidents as we have seen in some cases [13] are not very informative on their own, particularly not when we want to understand how to design new technology. Secondly we are concerned with the trend in 
Concerning the activity:

- Briefly describe the characteristics of the situation

- What did you do

- How did you do it

- What did you expect to happen

- What actually happened

What did you learn (tick off relevant cases):

- You accidentally discovered new features

- You used a trial and error strategy

- You got an idea about the way of working of

a the system and you tested your idea

- You got a completely revised view of what is offered by your tv

a Other

What served as means of help in this process:

a on the appliance indicated what I should do

a I read the manual

- I used my expectations from

a I talked to

I I had heard about from

口 Other

Figure 1. The incident diary

some of the work on remote usability testing of moving away from the users rather than approaching in direct engaging collaboration. In our case, we would have found it interesting to use the logging as a supplement to our approach of user driven hands-on use sessions to reconstruct the details of interesting events discovered in close collaboration with the users. Instead, we decided to develop a paper based form for the users to construct an incident diary. (Figure 1). 
Although in line with some of the others, e.g. Rieman [20] we are interested in learning and how the use is developing, we found that we have another perspective including the process of users buying, getting introduced to, and using a new television set. Thus we constructed our own specialised form in response to the characteristics of our specific study.

The diary was to be used by the user immediately after trying out new functionality or using a known functionality in another way. The idea was not to register in detail what actually happened. The diary should play the role as a reminder. Getting the users' diaries before our visits, we intended to use them in planning the following visit. Further, when visiting the families, the diaries should be used as a starting point for re-acting the situation. This use is different from any of the other diary studies we have come across where diaries are either supplemented with interviews [20], or automatic logging [12].

However, it turned out, that in our case the users did not use the diaries to any great extent. First, they found it difficult to fill in. What we asked the user to do was - as good as possible - to re-think what he or she was doing, why they did as they did and how it turned out. Discussing this with the users, we found that they had difficulties in remembering what they actually did, also just after it had happened. In this respect however, our form is only a subset of the critical incident reports [8], which has worked successfully in a constructed laboratory setting. Thus the problems we experienced may as well be due to the nature of the situation at home in which the diary was to be filled in, in our study. In using televisions at home users have different interest than filling in forms, i.e. telling other family members how to operate the functionality or just relaxing in front of their televisions. Thirdly, in our study, tasks were not constructed for the specific purpose of experimenting with the method, and with our visits every one and a half month, there were not many reminders for the users of the ongoing study.

Based on this study it is hard to conclude whether the diary failed due to the characteristics of the relaxed and private situation in the sofa in front of the television or whether it was due to the complexity of the specific form or insufficient preparation of the users. Nevertheless, our experiences suggests that what may be useful approaches to diary studies in constructed or work based situations may not prove useful for longitudinal studies in the home. Further investigations within the home sphere is necessary to shed more light on this.

In order to gain an understanding of how the users used the television and the problems they encountered on their way, we established situations where the users demonstrated for us, literally with their hands on the television and the remote control what had happened in interesting and critical situations. From our background in co-operative design, [10], this has previously turned 
out to be a very useful technique, at least in the workplace, to establish situations where users actively co-operate in the design process through assessing existing designs and envisioning future ones, [9]. We are not aware others having used such techniques before in the homes of users. As we shall argue in the following, this turned out to be a very useful technique, also in the home.

We set up scenario-framed hands-on use sessions which took as a starting point, the users' own reasons for buying the new television set, also covering things they would like to change in using their former television. These issues were at the first visit uncovered through interviews. Subsequently, at each visit we followed up on the themes raised by the users through constructing scenario framed hands-on use sessions, and we interviewed the users about things they had learned or tried out in the meantime, which could be followed up on immediately as well as next time.

An example from one of our families is the turning facility of the television where a small motor in the television allows the user, using the remote control, to make the television turn to each side such that the television easily can be turned from being directed towards the sofa section to e.g. the dining table. At our first visit in the family, lets call them Mary and John, Mary had explained how she really looked forward to exploiting this turning facility so that the television could easily be turned and the children would not stumble in the cords on the floor. Returning one month later, we followed up on this issue and asked them about whether the television had fulfilled their expectations in this respect. In response to this they first argued that it certainly had. We then presented them with the short scenario describing that they were now ready to have dinner and they wanted to watch the news while eating their meal. John then acted out how he would turn the television, and interestingly, John now got up, moved a big plant in their living room which was situated right next to the television, physically dragged the television a little away from the corner-wall it stood by and then grabbed the remote control to turn the television towards the dining table. Mary commented cheerfully that she was not able to do this because the television was too heavy. In our later visits they had moved the television such that the plant was no longer in the way and such that the TV could be turned more easily. However, still they had not found the perfect place for the television and from time to time, John still physically adjusted the television attempting to find a better place for it.

This example emphasises the value of studies in context also when we design for the home. The problem of finding the right position for the television in the physical configuration similar to John and Mary's where the television is positioned on a corner in the living room would not have been identified in a laboratory situation where the room would be arranged around 
the television, giving it a more "optimal" position. Further this situation illustrates the value of having users act out the situations, since this provides a much more detailed insight into how the television actually performs in its different roles and situations in the home.

\section{STUDYING EVERYDAY EVOLUTION OF USE IN THE HOME}

Traditionally, when studying usability within the field of Human Computer Interaction, we have focused on snapshots of use rather on how the use evolves in the everyday use of technology, [6]. We do so whether it is in a laboratory setting or on location, and whether it is in situ or as some kind of scenario.

Our long term research interest is the design of the interface, in this case a television set, and in how the design of the interface can support the users in evolving their use through using the technology. We have different reasons for this research interest, and for why it is particularly important to study how use evolves in the home. First, in homes users of television are not "forced" to use the television in the same way as users in a workplace, where the management have decided to buy some equipment. There are no demands from the context to use or how to use a television. The prime motives for using the television set is to get an experience and possibly because of having spent money on the product. Furthermore, as opposed to technology in workplaces, there is no tradition for formalised training or education in using home technology. On the contrary, from a salesman's point of view, there is an incentive to make the use of technology look as simple as possible, leaving the users with even larger troubles when learning to operate their television set. Bang \& Olufsen is aware of this problem and they have asked their sales personnel to guide the users through the operation of the products even when the users are studying them in the shop. Despite this, we saw incidents where the sales personnel made a quick rush through the different functionalities of the television at delivering, showing how easy it is to handle. Finally, the social situation is different in the homes than at workplaces. Lave and Wenger [17], and others have pointed out how learning often happens through what they term legitimate peripheral participation which comprises the notion that users gradually becomes practitioners of a certain practice, which in this case is the practice of using a television set, through watching and collaborating with more capable peers. However, in the use of televisions at home, most often only the small family acts as a community of practice. In addition, at rare occasions friends or the distributor can act as a more capable peers. 
Thus because of the special characteristics of the home in terms of the lack of enforcement to use the technology, the lack of formal training in using technology as well as few more capable peers present in the home, users who want to use home technology rely to a large extent on the design itself to support them in getting to use the technology as well as supporting the everyday evolution in use over time. Thus in order to design technology which supports users in evolving their use, we need to understand how use evolves in the home. Methodologically then, it is a challenge how to capture the learning process of the user. The challenges behind this question are then: how to study the use without introducing the possibilities and functionality which the users have not seen themselves, how to ask the family members about their use with out laying out the landscape of the product and finally, how to ask open questions.

\subsection{Capturing early evolution}

We designed our study such that the everyday evolution of use was in focus. This focus had consequences for the course of the study as well as the methods we used in collecting data in the field study. First of all, we chose to get into the use process as early as possible. In this way we got the possibility of studying how users initially adopt the television set as well as the further evolution of the use. The process starts even before the users buy the new equipment, it starts with the idea of new television, with the discussions in the families, with friends and others and with some visits at a distributor. We have not had the opportunity to deal with this part of the process. The owner of the boutique - quite naturally - gave top priority to selling his products and did not want to have the sale situation disturbed by people from outside, i.e. researchers. Thus, in this case, as early as possible meant at deliverance of the products in the homes. The distributor made the initial arrangement with the users and we accompanied the salesmen when they set up the televisions. Methodologically, this first meeting served several purposes. The project was presented for the family in our own words and we asked for their accept in participating. We saw how the salesman introduced the television to the customer and we made an initial interview concerning the users reasons for buying the television and their expectations to the television. Having their expectations as a starting point, we basically used three different methodological techniques in order to study the development process, iterative investigation, explorative inquiry and role playing. 


\subsection{Iterative investigation}

Our initial interview was crucial because it identified some of the reasons why the users bought the television set which we took as our point of departure. For instance, for one of the families a central aspect was the possibility to get surround sound from the television set. So at the first meeting after participating in the installation of the television set, we asked about this, and it turned out that the wife of the family had problems in turning the surround sound on, and we asked her to demonstrate how she would attempt to do so. At the next visit, we followed up on this by asking whether she had used the surround sound facility, and asked her again to demonstrate how she handled the problem in a hands-on scenario. By following-up on the same use situation from one visit to the next our approach had the nature of being an iterative investigation.

Having users act out situations with hands-on the technology turned out to be very useful, not only for understanding the general use of the technology in the home but also for studying evolution of use. In contrast to this, others have interviewed people about which general strategies they use when they approach and adopt new technology, [20]. However, based on our experience, questionable results are often obtained in this. Instead we would argue that it is important to discuss specific experiences with users and refrain from asking users to make generalisations about their behaviour. We illustrate how we have done this with an example from our study.

In one of our families, the woman, we can call her Sarah, had problems turning on multiple loudspeakers to obtain a surround sound effect with their television together with other parts of their hi-fi equipment. Right from the beginning, Sarah was very motivated to achieve this surround sound effect in their living room, however, at our second visit, she was still not able to accomplish this on her own. We asked her about how she would approach this task, what sources of help she would seek, and she explained with great conviction how she would consult the manual to find out how to do. She even praised the structure of the manual, and argued that it was very easy to use. When we returned one month later, she had, through experimentation and exploration, found out how to switch on the loudspeakers and she was very proud. We asked her to demonstrate how she had accomplished this and she demonstrated to us how she did it now, explaining what had confused her the first times with references to how she did it now. Interestingly, when we asked about the role of the manual in her discovery she explained that she had not used the manual at all in this situation. She now argued that:

"when you want it to work, and if you are alone one day... and there is
something you want to watch ... then you become stubborn and start to 
experiment, because you do not have any other options...... oh you do have the manual, but before you get started to flick through that then the movie is already started".

Although this general explanation probably should not be taken for its face value either, we can ascertain that in this specific situation, it certainly was not the manual who helped Sarah accomplish her task despite her earlier praise of the manual as a tool in this respect.

\subsection{Explorative inquiry}

A general quality of our way of approaching the users has been to ask open questions which has been particularly important in our objective to study evolution of use where it is crucial to avoid asking questions which disclose the facilities of the technology. So for instance we would ask "Have you tried any new things since last visit?" rather than ask "Have you used Text-TV programming?"

Within the area of therapy it is crucial that the client themselves formulate their problems. In order to support this process it is crucial to ask questions offering the client the possibility to formulate his or her own view of the situation without searching for a specific answer. We have been inspired by Hammond, [11], who writes about how to make interviews and investigations linking to what the person says. As the focus for the study we had a whole range of issues related to evolution in use, but rather than systematically going through them at each visit we listened to what the family members said and used that as the platform for the subsequent part of the visit. So when we had asked the family about new things they have tried, we asked them how they attended to the functionality, how they tried it out the first time, and whether they used some support in terms of manual or other people etc.

\subsection{Role play}

We experimented with role play as an approach to gain insight into the users' current understanding of the television and its possibilities without influencing the adoption processes. As an example, we wanted to know whether the users had made any use of the television as an alarm clock, using the facility which allows them to program the television to start and stop at certain times. It could be tempting just to ask them about this, but in doing so, we would have pointed to this possibility in the television. Since we are interested in studying the process of how users discover and start to use different facilities we did not want to disturb this process. In order to 
avoid this, we set up a role play. The idea was that the family should imagine that we, i.e. the researchers were their friends who had come to visit them and who were in the process of buying a new television set. Therefore, we would like the family members to show us their television and explain to us as their friends, what aspects they would recommend and if there was something, which annoyed them about their television. Again, this was an attempt to ask very open ended questions and to engage the users in active co-operation.

Once again, it turned out to be a good idea to ask open ended questions. What happened in the role play, though, was different from our expectations. We had expected the users to make more references to the fancy features of the operational aspects of the television but interestingly, the level of the explanations varied significantly between the different individuals. As an example, while one of the users praised the appearance and aesthetics of the television and how that fitted well in their home, another focused much more on how easy it was to use teletext to program their video to record, which for him was an important feature of the television. Thus this approach turned out to be useful in the way that it allowed the users, in their own words to describe how they perceived their television and to emphasise the aspects that were particularly interesting for them with direct reference to the television demonstrating what they meant. What was a positive surprise to us was that the role play was a means for us to understand more fundamentally the different roles the television played in the different families and for the different individuals.

\section{CONCLUSION}

Our study suggests that diary studies may be problematic for longitudinal studies in the home where users are not reminded of the ongoing study and are concerned with other things such as relaxing or even sleeping in front of the television. However, more studies are needed to explore this issue further. A lack of training as well the specific diary form in our study may also have been critical factors which left the diaries practically unused.

In contrast, participatory design techniques with hands-on demonstrations of use turned out to be fruitful not only in work settings but also in the home for understanding the details of how people interact with the technology as well as how their use develops the means that support this. By relying on how people, through active demonstrations and with references hereto, explain how they learned to operate the technology, more reliable and interesting accounts are obtained than what can be obtained through 
interviews where the users are asked to provide generalised characterisations of their way of dealing with technology in the home.

Evolution in use was studied by starting out from the expectations of the users and subsequently we basically used two methodological techniques in order to study the development process, iterative investigation and explorative inquiry. Moreover role playing has been used.

\section{REFERENCES}

[1] Baxter, I. \& Oatley, K. (1991) "Measuring the learnability of spreadsheets in inexperienced users and those with previous spreadsheet experience". In Behaviour \& Information Technology, Vol. 10, No. 6, pp. 475-490.

[2] Blomberg, J., Giacomi, J., Mosher, A., Swenton-wall, P. (1993): Etnographic Field Methods and Their Relation to Design, in: Schuler, D., Namioka, A. (Ed.): Participatory Design: Principles and Practices, Hillsdale: Lawrence Earlbaum Associates, pp. 123-155

[3] Blomberg, J., Suchman, L. \& Trigg, R. (1994): Reflections on a work-oriented design project. In Trigg, R., Anderson, S. \& Dykstra-Erickson, E. (Eds.): PDC 94 Proceedings (99-109).

[4] Brown \& Duguid (1991) “Organizational Learning and Communities-of-Practice. Towards a Unified View of Learning, Working and Innovation". In Organisational Science, Vol.2, no. 1.

[5] Bødker, S. (1999). "Scenarios in user-centred design - setting the stage for reflection and action. Hawaii International Conference on System Sciences 32.

[6] Bødker, S. \& Petersen, M. G. (submitted for publication) Designing for learning in use.

[7] Carroll, J. M. (Ed.) (1995) Scenario-Based Design - Envisioning Work and Technology in System Development John Wiley \& Sons, Inc.

[8] Castillo, J. C., Hartson, H. R. \& Hix, D. (1998) "Remote Usability Evaluation: Can Users Report Their Own Critical Incidents ?" In Proceedings of the CHI 98 summary conference on CHI 98 summary: human factors in computing systems 1998, ACM Press, pp. 253-254.

[9] Ehn, P. \& Kyng, M. (1991) "Cardboard Computers: Mocking-it-up or Hands-on the Future" in Greenbaum, J. \& Kyng, M. (eds.) Design at Work: Cooperative Design of Computer Systems. Hillsdale, N.J.: Lawrence Erlbaum Associates, pp. 169- 196.

[10] Greenbaum, J. \& Kyng, M. (Eds.)(1991). Design at Work: Cooperative Design of Computer Systems. Hillsdale, N.J.: Lawrence Erlbaum Associates.

[11] Hammond, Sue A.: The Thin Book of Appreciative Inquiry, Kodiak Consulting, Texas, 1996

[12] Kaasgaard, K., Myhlendorph, T., Snitker, T. \& Sørensen, H. E. (1999) "Remote Usability Testing of a Web Site Information Architecture: Testing for a Dollar a Day". In Sasse, M. A. \& Johnson, C. (Eds.), Human-Computer Interaction-INTERACT '99. IOS Press, pp. 443- 450 .

[13] Kay \& Thomas (1995) "Studying Long-Term System Use". In Communications of the ACM, ACM Press.

[14] Kraut, R. (1996) The Internet at Home (Introduction to special issue) In Communications of the ACM, December 1996, Vol. 39, No. 12, ACM Press, pp. 32-35. 
[15] Kuutti, K. (1999) "Small Interfaces - a blind spot of the academical HCI community ?" In Proceedings of HCI International '99. München, August 20-27, 1999.

[16] Kyng, M. (1995) “Creating Contexts for Design". In Carroll, J. M. (Ed.), Scenario-based design. Envisioning work and technology in system development. Wiley, New York, NY, 1995, pp. 85-108.

[17] Lave, J. \& Wenger, E. (1991). Situated Learning. Legitimate peripheral participation. Cambridge University Press.

[18] Mackay, W. E. (1995). "Ethics, Lies and Video" in Proceedings of the CHI 95 human factors in computing systems, ACM Press, pp. 253-254.

[19] O'brien, J. \& Rodden, T. (1997) Interactive Systems in Domestic Environments. In DIS '97, Amsterdam, The Netherlands, ACM.

[20] Rieman, J. (1996) "A Field Study of Exploratory Learning Strategies". In ACM Transactions on Computer-Human Interaction, Vol.3, No. 3, September 1996, pp. 189-218

[21] Rijn, F. van \& R. Williams (Eds.) (1988). Concerning Home Telematics. Amsterdam: North-Holland.

[22] Rosson (1983) "Experiences in Text Editing" in Proceedings of the CHI 83: human factors in computing systems, ACM Press.

[23] Suchman, L. A. \& Trigg, R. H. (1991) "Understanding Practice: Video as a Medium for Reflection and Design". In Greenbaum, J. \& Kyng, M. (Eds.) Design at Work: Co-operative Design of Computer Systems. Hillsdale, N.J.: Lawrence Erlbaum Associates, pp. 65-89. 